\title{
ОТВЕТСТВЕННОСТЬ СЕМЬИ В ПРОЦЕССЕ РОСТА РАСПРОСТРАНЕННОСТИ ОЖИРЕНИЯ В ДЕТСКОМ ВОЗРАСТЕ
}

\author{
Е.Г. Михайлова, О.В. Скворцова \\ ГБУЗ СОДКБ им. Н.Н. Ивановой, Самара
}

\begin{abstract}
ВВЕДЕНИЕ: В течение последних лет распространенность ожирения прогрессивно увеличивается, в том числе и среди детского населения, несмотря на повсеместно принятые меры: дополнительные уроки физкультуры, бесплатные спортивные секции, школьное питание, обширную просветительскую работу в школах и других учреждениях, массовую пропаганду здорового образа жизни в социальных сетях, проведение ежегодных профилактических осмотров. Именно этапы профилактических осмотров дали большой повод для размышления и показали весомые камни преткновения в решении проблемы избытка массы тела и ожирения в детском возрасте.
\end{abstract}

ЦЕЛЬ: оценить тенденцию роста ожирения среди детского населения,

МАТЕРИАЛЫ И МЕТОДЫ: проведение ежегодного профилактического осмотра школьников. Были оценены параметры физического развития 2971 ребенка 2002-2010 г. рождения.

РЕзУЛЬтАТЫ: Из этого количества детей выявлено 425 (14\%) человек с избытком массы тела и 992 (33\%) с ожирением. Причем распространенность и того и другого была практически одинакова во всех возрастных группах (10-17 лет). Обращает на себя внимание преобладание ожирения над избытком массы тела, чего не было 10-15 лет назад: тогда избыток веса составлял 10-12\%, ожирение 4-6\%, сейчас же избыток веса встречается у $10-21 \%$, ожирение - $27-42 \%$. Все дети с диагнозом ожирение были приглашены на 2 этап диспансеризации, включающий в себя обследование в соответствии с клиническими рекомендациями и дальнейшее наблюдение у эндокринолога.

Практически из тысячи приглашенных детей на прием к эндокринологу в течение первых трех месяцев после получения направления пришла только десятая часть. В течение года из этих приглашенных детей посетили специалиста около 35\% пациентов. Причем основная масса была вынуждена прийти из-за настойчивости школьного врача-педиатра, так как приглашение на реализацию 2 этапа входит в их непосредственные обязанности. Обращает на себя внимание, что большую часть пациентов 2 этапа составили дети. Количество подростков было значительно меньше. Также, основная масса приглашенных по разным причинам приходила на прием без родителей, объясняя это их занятостью. В дальнейшем, по прошествии двух лет регулярно наблюдались у эндокринолога около 5\% детей, а имели длительную положительную динамику лишь единицы. Косвенным доказательством этой печальной статистики служат официальные данные запроса 2016 г. по Самарской области по обращаемости детского населения к эндокринологу с диагнозом ожирения: всего количество обращений среди детей составило 9876 человек, среди подростков - 3278. Из них регулярно посещали врача только 3994 ребенка и 961 подросток.

При совместном анализе обстоятельств и причин, способствующих такому росту распространенности заболевания вместе с родителями, стоит уделить внимание некоторым вещам: несмотря на широкую распространенность школьного питания, при всех школьных столовых присутствует продажа сдобной выпечки и сладких напитков. Большое количество детей предпочитает что-то купить взамен школьному обеду или после основного приема пищи дополнительно. Некоторые дети не состоят на школьном питании, имея другие предпочтения в еде. Родители же в свою очередь потворствуют таким привычкам, часто питаясь подобным образом и дома. На выходных во многих семьях становится традицией питаться в торговых центрах фаст-фудом, что для родителей является вариантом нормы. Нельзя оставить без внимания и уровень медицинской грамотности родителей. Многие из них обратились к эндокринологу впервые, не считая лишний вес проблемой. Часть из них становится настроена негативно, слыша о диагнозе и рекомендациях по смене образа жизни и пищевых привычек в семье. Те родители, 


\section{СБОРНИК ТЕЗИСОВ}

XVII Российская научно-практическая конференция детских эндокринологов

«Достижения науки в практику детского эндокринолога»

которые проблему принимают, в основной массе никогда не пробовали решить ее самостоятельно и пересмотреть семейный уклад. Также стоит отметить, что многие дети не посещают спортивные секции из-за невозможности или нежелания родителей тратить время на то, чтобы отвести и встретить ребенка с занятия.

Вывод: невозможно бороться с формированием избыточного веса у ребенка, привлекая только силы медиков, педагогов, средств массовой информации, значительную роль в этом вопросе играет степень заинтересованности и ответственности семьи ребенка. На сегодняшний день образ жизни и пищевые привычки семьи можно считать одним из факторов риска развития ожирения у детей, а степень ответственности - прогностическим признаком исхода проблемы. 